\title{
Impact of Diabetes on Postinfarction Heart Failure and Left Ventricular Remodeling
}

\author{
Helene von Bibra • Martin St John Sutton
}

Published online: 13 August 2011

(C) The Author(s) 2011. This article is published with open access at Springerlink.com

\begin{abstract}
Diabetes mellitus, the metabolic syndrome, and the underlying insulin resistance are increasingly associated with diastolic dysfunction and reduced stress tolerance. The poor prognosis associated with heart failure in patients with diabetes after myocardial infarction is likely attributable to many factors, important among which is the metabolic impact from insulin resistance and hyperglycemia on the regulation of microvascular perfusion and energy generation in the cardiac myocyte. This review summarizes epidemiologic, pathophysiologic, diagnostic, and therapeutic data related to diabetes and heart failure in acute myocardial infarction and discusses novel perceptions and strategies that hold promise for the future and deserve further investigation.
\end{abstract}

Keywords Diastolic dysfunction · Tissue Doppler.

Metabolic syndrome - Type 2 diabetes - Insulin resistance .

Cardiovascular disease $\cdot$ Left ventricular remodeling $\cdot$ Intact proinsulin . Low carbohydrate diet

\section{Introduction}

The striking increase in the worldwide prevalence of the metabolic syndrome parallels the epidemics of obesity and

H. von Bibra $(\bowtie)$

Klinic for Endocrinology, Diabetes and Vascular Medicine, Klinikum Bogenhausen, Städtische Klinikum München GmbH, Englschalkingerstrasse 77,

81925 München, Germany

e-mail: vonbibra@gmx.de

M. St John Sutton

Department of Medicine, Cardiovascular Division,

University of Pennsylvania School of Medicine,

Philadelphia, PA 19106, USA diabetes [1]. Type 2 diabetes mellitus and insulin resistance are established risk factors for heart failure (HF) $[2,3]$. Many patients with diabetes have diastolic dysfunction [4] that is the antecedent in the increasing prevalence of HF with preserved ejection fraction [5••]. Similarly, systolic HF and coronary artery disease (CAD), including myocardial infarction (MI), are interlinked in a reciprocal relationship. Diabetes has been a consistently powerful risk factor for development of post-MI HF, accounting for $66 \%$ of mortality during the first year [6]. The combination of diabetes and $\mathrm{HF}$ after MI requires preventive action because it is usually not associated with the characteristic left ventricular (LV) remodeling [7]. If LV remodeling does develop, it requires appropriate treatment [8] that includes revascularization and metabolically and hemodynamically effective treatment strategies that limit infarct size, cardiac dysfunction, and LV remodeling. This review summarizes epidemiologic, pathophysiologic, diagnostic, and therapeutic data related to diabetes/metabolic syndrome and HF and LV remodeling post-MI.

\section{Pathophysiological Impact of Diabetes on Heart Failure and Remodeling}

Several mechanisms promote metabolic consequences that lead to cardiac dysfunction and HF in diabetes. The primary etiology of the metabolic syndrome in type 2 diabetes is chronic overnutrition resulting in insulin resistance, abdominal obesity, hyperinsulinemia, and lipotoxicity. Another important mechanism deduced mainly from experimental work is myocardial energy demand/supply mismatch from 1) increased oxygen demand in the diabetic myocardium related to increased vascular stiffness; and 2) decreased energy supply from myocardial underperfusion, 
endothelial dysfunction, and reduced myocellular energy production. This energy mismatch is associated with increased stress in the infarct-related segments and neurohormonal upregulation in the remote zones.

\section{Increased Myocardial Energy Demand}

Increased myocardial oxygen consumption $\left(\mathrm{MVO}_{2}\right)$ has been observed in human studies and in experimental diabetes models $[9,10]$. Similarly, increased myocardial energy demand assessed by increased rate pressure product has been demonstrated at rest and during stress in patients with type 1 [11] and type 2 diabetes [12, 13]. This observation has been ascribed to increased arterial wall stiffness as an important determinant for increases in systolic blood pressure and pulse pressure [14, 15].

\section{Decreased Myocardial Energy Supply}

\section{Microvascular Perfusion Abnormalities}

In patients with diabetes, the increased incidence of HF post-MI is mainly due to a diminished microvascular perfusion after reperfusion therapy [16], and a reduced coronary flow reserve is consistently observed at cardiac catheterization. The modulation of myocardial blood flow at the level of microcirculation is achieved from blood volume changes from the recruitment or derecruitment of capillaries. The only diagnostic method that provides insight into this aspect of perfusion, dedicated to metabolic substrate exchange, is myocardial contrast echocardiography. The microbubbles residing strictly within the lumen of the capillaries enable assessment of myocardial capillary volume index, flow velocity, and myocardial blood flow index [17, 18]. A consistent observation in patients with diabetes without CAD is a decreased capillary volume at stress by a diminished stress-induced increase ( $17 \%$ vs $50 \%$ in control patients) [11-13]. Factors contributing to this limited response are hyperglycemia, hyperlipemia, oxidative stress, and endothelial dysfunction present in any postprandial phase $[19,20]$. After a physiologic mixed meal (400 kcal), a 50\% reduction in capillary blood volume was demonstrated in patients with diet-treated type 2 diabetes, but not in control patients [21]. Translating this effect into the setting of acute MI in coronary care units highlights the additional risk of undetected myocardial hypoperfusion in each postprandial phase for diabetic patients. The regulation of capillary recruitment is dynamic and improves with glycemic control in the fasting and postprandial states as well as with cardiovascular preventive medication, as demonstrated in small human studies $[13,22,23]$. These data indicate that capillary volume modulation plays an important but little acknowledged role in the regulation of human myocardial perfusion requiring prospective investigations.

\section{Endothelial Dysfunction}

Endothelial dysfunction is an early abnormality in CAD, obesity, and the metabolic syndrome with insulin resistance and an imbalance between the reduced bioactivity of nitric oxide and endothelin-1. Additional inducing factors are hyperglycemia, hypercholesterinemia, and hypertension. Augmentation has been observed after the intake of oleic acid (eg, olive oil), antioxidants (eg, vegetables, fruit, and vitamins $\mathrm{C}$ and $\mathrm{E}$ ), and the phenolic compounds in red wine. Pharmaceutical improvement has been achieved with insulin, statin, angiotensin-converting enzyme (ACE) inhibitors, and angiotensin- 1 blockers or with thiazolidinediones (TZDs). Abnormalities of flow-mediated vasodilation of the brachial artery [24] are considered to be markers of abnormal myocardial perfusion, but the mechanisms of regulation may differ in these vascular territories.

\section{Reduced Myocardial Energy Production}

Patients with diabetes have reduced regional function in the noninfarct zone despite a similar ejection fraction compared to control patients without diabetes, and have a two- to threefold greater incidence of HF after acute MI [7, 25]. Multiple studies have suggested that diabetes is associated with a cardiomyopathy characterized by diastolic abnormalities [26, $27 \cdot 0$ ] and higher chamber stiffness, independent of hypertension and $\mathrm{CAD}[25,28 \bullet]$. Although increased chamber stiffness usually is thought to result from structural myocardial alterations such as hypertrophy, fibrosis, and modifications of the extracellular matrix, it is often due to myocardial relaxation abnormalities secondary to energy restraints from acute hypoxemia, ischemia, or metabolic stress [29].

In the normal heart, $70 \%$ of myocardial energy production is derived from free fatty acid (FFA) oxidation. During stress or hypoxia, this is shifted to more glucose oxidation that requires less oxygen for adenosine triphosphate (ATP) production. However, in insulin resistance, glucose uptake and oxidation are suppressed and myocytes remain almost completely dependent on the use of FFA oxidation. Additionally, increased FFA levels together with insulin resistance promote synthesis of uncoupling proteins, resulting in the production of heat instead of ATP, so that up to a $40 \%$ decrease in ATP production may result compared to glucose oxidation [30]. This inability to switch fuels also may lead to generation of reactive oxygen species (ROS) and unfavorable alterations in calcium metabolism. These adverse metabolic effects are induced by insulin resistance and effectively contribute to HF also in patients with diabetes by sustaining neurohormonal activation. 
Lipotoxicity and Glucotoxicity

\section{Lipotoxicity}

Strongly related to insulin resistance, obesity is a known risk factor for HF [31]. Animal studies suggest that the underlying mechanisms are overstorage of lipids and lipotoxic injury to myocytes associated with high serum levels of FFA and triglycerides that involve increased FFA uptake, diminished mitochondrial oxidative capacity, generation of ROS, and increased apoptosis [32]. Of particular importance, insulin resistance alters the distribution pattern of postprandial energy storage after ingestion of a highcarbohydrate mixed meal away from glycogen synthesis in skeletal muscle cells to de novo hepatic production of triglycerides (lipogenesis). This increase in plasma triglycerides and decrease in high-density lipoprotein (HDL) concentration [33••] implies that carbohydrate restriction may improve serum lipid values. Compared to lean control patients, increasing intracardiac lipid storage was demonstrated in overweight individuals, individuals with additional impaired glucose tolerance, and individuals with overt type 2 diabetes in a magnetic resonance imaging (MRI) study [34]. Furthermore, in patients with diabetes, cardiac steatosis correlates with diastolic dysfunction [35].

\section{Glucotoxicity}

Lipotoxicity is an important mechanism in the metabolic syndrome. In patients with lipotoxicity, glucotoxicity plays an intermittent role only during significant hyperglycemia in the postprandial phase lasting for up to $2 \mathrm{~h}$. However, in overt diabetes, postmeal hyperglycemia is prolonged to at least $4 \mathrm{~h}$, so that glucotoxicity exacerbates the metabolic consequences of chronic overnutrition during most of the day.

Glucotoxic effects involve three additional mechanisms for dysfunction in the diabetic heart. These involve 1) ROS that amplify hyperglycemia induced activation of protein kinase C isoforms; 2) increased formation of glucosederived advanced glycation end products; and 3) increased glucose flux through the aldose reductase pathways [32]. Admission glucose levels have a prognostic role in patients with acute MI and in patients with HF [36, 37].

\section{Oxidative Stress (Reactive Oxygen Species)}

ROS also play a role in the disturbed glucose and lipid metabolism in chronic overnutrition that may be generated by both the hyperlipidemia and hyperglycemia pathways. After a carbohydrate meal, ROS increases in overweight patients with diabetes but not in lean control individuals (von Bibra, unpublished data; [20]). In the context of diastolic dysfunction, it is striking that many mechanisms activated by an increased generation of ROS lead to reduced availability of energy. The direct effects of ROS on cardiomyocytes involve impaired mitochondrial energy production [38・• and reduced cardiac efficiency [32]. Further effects imply altered insulin signaling, reduced availability of nitric oxide, and mitochondrial damage that can lead to abnormal cardiac structural and functional remodeling [26, 39]. Indirect effects may involve downregulated perfusion by endothelial dysfunction [40].

\section{Neurohormonal Alterations}

Another primary mechanism linking HF, diabetes, and insulin resistance is upregulation of the sympathetic nervous system and the renin-angiotensin system during reduced cardiac output that may lead to a vicious cycle via increases in circulating FFA concentrations [41]. Different mechanisms, affecting heart rate regulation and exercise tolerance, are implicated in cardiac autonomic neuropathy. Additionally, in HF and in LV remodeling, inflammatory mediators are upregulated, the most prominent being tissue necrosis factor- $\alpha(\mathrm{TNF}-\alpha)$. Insulin resistance is associated with upregulation of the same inflammatory pathways that can be attenuated by insulin sensitization treatment. However, this has been largely unsuccessful in human clinical trials because only individual components of the inflammatory cascade have been targeted [38••].

\section{Impact on Diagnostics}

Because of the numerous interactive metabolic pathways and their metabolic, hemodynamic, and functional consequences, we will focus on causal mechanisms and insulin resistance rather than symptoms or consequences. Because insulin resistance is a nutritional disease, relevant diagnostic methods for assessing postmeal metabolism and severity of insulin resistance are discussed.

\section{Insulin Resistance and Diabetes}

Clinicians lack a grading system for type 2 diabetes. Occasionally, the type of therapy (diet vs oral antidiabetics vs insulin) has been used as a substitute. Type 2 diabetes is the result of two developments: 1) chronic overnutrition with resulting insulin resistance and 2) at least a relative failure of pancreatic B-cells to release sufficient insulin to maintain glucose homeostasis. In this context, insulin resistance is the basic mechanism, but its diagnosis is not straightforward. Commonly, attempts are made using the homeostasis model of insulin resistance [42]. This measure may be misleading in the phase of failing $\beta$-cell function and during insulin-based therapy. Intact proinsulin is a 
precursor molecule of insulin that is released into circulation, is associated with increasing insulin resistance, and has a similar adipogenetic activity to insulin but only $10 \%$ to $20 \%$ of the glucose-lowering effect. Recently, determination of proinsulin has been used as a diagnostic tool because an increasing proinsulin to insulin ratio predicts insulin resistance and deterioration of glucose tolerance [43]. Increasing intact proinsulin reflects increasing $\beta$-cell dysfunction. Thus, both measures are useful biomarkers for insulin resistance and $\beta$-cell dysfunction and for assessing the impact of therapeutic intervention on $\beta$-cell function in type 2 diabetes $[44,45]$. Such a diagnostic tool would allow staging of patients with diabetes for appropriate antidiabetic therapy and establishing the risk of insulin resistance in obese patients $[46 \cdot \bullet]$.

Finally, in the setting of acute MI and revascularization, blood glucose control in patients with diabetes should routinely involve fasting and postmeal glucose measurements (such as hyperglycemic peaks with the associated sequelae of hyperinsulinemia, ROS generation, and endothelial dysfunction) because only the latter reflects the amount and type of ingested carbohydrates [20, 21, 47].

\section{Diastolic Cardiac Function}

The traditional assessment of diastolic and systolic LV function by mitral inflow pattern and LV ejection fraction has been largely superseded by parameters derived from quantitative tissue Doppler imaging involving LV longitudinal function during diastole and systole [48, 49] and assessment of LV filling pressure [50, 51]. Assessment of regional and global LV function in acute $\mathrm{MI}$ and $\mathrm{LV}$ remodeling requires parameters that are feasible even in overweight individuals at the bedside, are sensitive to energy restraints, and, ideally, have prognostic value and the ability to monitor therapeutic interventions. Early diastolic function is more sensitive to changes in myocardial perfusion than systolic function as shown in human and animal studies with percutaneous transluminal coronary angioplasty, a model with a precise onset and end of myocardial perfusion $[52,53]$. Because the early diastolic filling period is short (approximately $100 \mathrm{~ms}$ ), accurate measurement of early diastolic velocity/function requires high temporal resolution of the imaging technique (frame rate $>100$ frames/s), which is provided by pulsed tissue Doppler and in high-quality color Doppler systems, but not with MRI [27••]. Pulsed tissue Doppler imaging has the additional advantage of online velocity quantification based on fast Fourier transform analysis and, importantly, has good feasibility even in individuals who are difficult to image with 2-dimensional echocardiography [54, 55]. Furthermore, the influence of aging on diastolic function may be used to define diastolic dysfunction $[12,27 \bullet \bullet]$, which is critical for the diagnosis of diastolic HF and dysfunction [50, 51]. The advantages of tissue Doppler-based velocity measurements should not detract from advantages of other ultrasound techniques, such as myocardial strain and strain rate analysis using speckle tracking, which permits assessment of regional and global myocardial function.

\section{Microvascular and Endothelial Function}

Myocardial contrast echocardiography, as described above, is a technique yielding specific information on microvascular myocardial perfusion at the bedside in the setting of acute MI, after myocardial revascularization, and in endothelial dysregulation from insulin resistance. Although standardized by the American and European Societies of Echocardiography [56, 57], myocardial contrast echocardiography has not yet found acceptance into routine clinical practice. It needs the commitment of clinicians to learn how to use this imaging technology for diagnostic insight $[18,58 \bullet \bullet]$.

Myocardial metabolic remodeling as a consequence of utilizing different substrates may be assessed by specialized imaging techniques, such as single-photon emission computed tomography, positron emission tomography, and magnetic resonance spectroscopy [59]. Finally, endothelial dysfunction and respective treatment effects may be assessed by flow-mediated vasodilation [24].

\section{Impact on Treatment Options}

\section{Nutrition}

Adequate composition of food intake is the cornerstone of managing nutritional disease, such as insulin resistance and type 2 diabetes. The official recommendations in Europe and the United States have consistently promoted food that contained little fat (approximately 25\%) and a substantial amount of carbohydrates $(45 \%-60 \%)[60,61]$. The result of low fat and high carbohydrate consumption in the United States is an increasingly obese population [62・•]. The results of the INTERHEART study [63] raised increasing concerns about these recommendations and led to reconsideration of the physiologic principles of metabolism: carbohydrate restriction improves glycemic control and reduces insulin fluctuations, which both are primary targets that do not need weight loss [64••, 65•] but improve all features of the metabolic syndrome. Positive effects on insulin resistance, serum triglyceride and HDL levels, glucose control, and cardiovascular risk factors have been consistently demonstrated without any adverse effects, given the need to reduce antidiabetic medications stepwise (by $50 \%$ to $80 \%$ ) to avoid hypoglycemia. The beneficial effects of low-carbohydrate diets have been confirmed in 
randomized long-term studies [66, 67]. Noteworthy, beneficial effects of carbohydrate restriction on postmeal endothelial dysfunction were demonstrated in individuals with abdominal obesity and in those with atherogenic dyslipidemia $[68,69]$.

Improved cardiac function by low-carbohydrate nutrition in type 2 diabetes was shown in a pilot study or indirectly via tight caloric restriction (400 kcal per day) in obese individuals with diabetes [70, 71]. In severe obesity, randomized long-term studies have confirmed improvement in cardiac function after weight loss due to a low glycemic index diet or bariatric surgery [72]. Large dietary studies based on reduced caloric intake by increased vegetable consumption have proven benefits for CAD risk [73].

Extending their traditional recommendations, the American Diabetes Association in 2008 stated that low-glycemic index foods (ie, between 40 and $130 \mathrm{~g}$ /day of low-glycemic carbohydrate or less than $26 \%$ of a nominal $2000 \mathrm{kcal}$ diet) that are rich in fiber and other macronutrients may improve outcome [60].

There now is ample evidence that the nutritional therapy in type 2 diabetes with insulin resistance should be carbohydrate restriction. The available studies did not reveal any associated harm. If such a straightforward approach can alleviate a condition for which there is no known effective drug, its potential should be vigorously applied and explored.

\section{Insulin Sensitizers}

Because of the basic and adverse consequences of insulin resistance in patients with diabetes, this review focuses on insulin sensitizers such as biguanides, TZDs, and glucagonlike peptide 1 (GLP-1).

Metformin has been associated with improved outcome in both the prospective United Kingdom Prospective Diabetes Study and in patients with diabetes and HF in an observational Canadian study $[74,75]$. More recently, it was shown to improve LV diastolic function [76]. Unfortunately, the use of metformin is contraindicated because of a perceived increased risk of lactic acidosis in HF, although the supporting evidence is lacking both for lactic acidosis and for the policy of stopping metformin $48 \mathrm{~h}$ before and after procedures in cardiac patients [77]. A recent meta-analysis on the use of antidiabetic drugs in patients with HF concluded that metformin was not associated with any adverse events, but instead had a reduced mortality risk [78].

TZDs were designed to increase insulin sensitivity. However, prospective studies are scarce because of the warnings against the use of TZDs in patients with HF symptoms [79]. More recent data suggest that these risks are controllable and acceptable, being in the range of 5\% to $15 \%$ for TZD-induced fluid retention that is part of the insulin-sensitizing action in the renal collecting ducts, but not necessarily a symptom of worsening myocardial function [80]. In patients with diabetes without cardiac disease, diastolic function was improved by pioglitazone in an MRI study [81]. In patients with HF (New York Heart Association class I-II), rosiglitazone improved glycemic control and did not adversely affect LV ejection fraction [82]. Observational data and a retrospective study reported some reduction in the risk of death despite a smaller increase in the risk of readmission for HF by the use of TZDs [83, 84]. Recently, concerns have been raised regarding the cardiovascular side effects of rosiglitazone, which now is available in the United States with additional restrictions but is not available any more in Europe.

First promising results were shown by GLP-1, which is secreted in the intestine in response to oral ingestion of glucose and stimulates insulin secretion, suppresses glucagon secretion, delays gastric emptying, and increases satiety. Because of its short half-life (1-2 $\mathrm{min})$ due to cleavage by the ubiquitous dipeptidyl peptidase-4 (DPP-4), long-acting analogues of GLP-1 (exenatide, liraglutide) and inhibitors of DPP-4 (sitagliptin, vildagliptin, saxagliptin, linagliptin, and alogliptin) have been developed.

GLP-1 does not cause hypoglycemia and has promising effects on the cardiovascular system. Nitric oxide-dependent endothelial function is increased in healthy individuals and in patients with diabetes $[85,86]$. Both GLP-1 and its analogue exenatide reduce ischemia/reperfusion injury in experimental studies. There are small human studies demonstrating beneficial effects of GLP-1 on LV ejection fraction in ST-elevation anterior MI with LV dysfunction after successful reperfusion [87]; in coronary artery bypass grafting [88]; and in HF [89]. Also, the use of DPP-4 inhibitors demonstrated beneficial effects on postprandial glycemia, lipidemia, and oxidative stress in patients with type 2 diabetes $[90,91]$ and, after a single morning dose, on postprandial endothelial function [92]. DPP-4 inhibitors administered before an oral load of glucose, $75 \mathrm{~g}$, demonstrated improved LV performance and mitigated stunning during dobutamine stress in patients with CAD, but undefined as for coexisting diabetes [93]. Further studies are needed to determine whether synthetic GLP-1 mimetics and DPP-4 inhibitors are able to reproduce the beneficial effects of GLP-1. Some answers may be expected from ongoing studies on cardiovascular outcomes in patients with diabetes with GLP-1 analogues or DPP-4 inhibitors. These studies focus on diabetic metabolism (efficacy of lowering blood glucose in coronary care unit or of maintaining $\beta$-cell function), on the limitation of infarct size in acute coronary syndrome, or on global myocardial function in combination with granulocyte-colony stimulating factor and cardiovascular risk. 
Glucose-lowering Antidiabetic Therapy

A large body of clinical studies intending to improve outcomes through tight glycemic control have produced controversial results and conflicting implications for optimal antidiabetic therapy in at-risk patients with CAD [94・•]. Despite the evidence that glucose control matters in patients with diabetes, more cautious approaches are required to avoid the risks from increased hypoglycemic events in tight control and other complications associated with the intensity of pharmacological treatment with several antidiabetic drugs simultaneously. These concerns led to new official treatment recommendations in $2008[95,96]$ that suggested aggressive glucose control for patients in intensive care units with significant hyperglycemia $(>180 \mathrm{mg} / \mathrm{dL}$, $10 \mathrm{mmol} / \mathrm{L}$ ) to target glucose values between 90 and $140 \mathrm{mg} / \mathrm{dL}(5-7.8 \mathrm{mmol} / \mathrm{L})$ and, for the other hospitalized patients, subcutaneous insulin for maintaining plasma glucose levels lower than $180 \mathrm{mg} / \mathrm{d}(10 \mathrm{mmol} / \mathrm{L})$.

Given the major impact of postprandial hyperglycemia on metabolic complications, it is of concern that most therapeutic studies ignore this measurement. In addition, the different stages of insulin resistance should be taken into account for therapeutic strategies aimed at achieving an ideal glucose target. Finally, with respect to the nutritional induction of postprandial hyperglycemia (particularly in type 2 diabetes), carbohydrate restriction may circumvent the dangers of insulinemic and hyperglycemic peaks in insulin resistance without the risk of hypoglycemic events once antidiabetic therapy is adapted to the nutritional and metabolic changes, and without the risk of side effects from multiple glucose-lowering drugs. Applying such causal therapy, a fasting serum glucose level around $110 \mathrm{mg} / \mathrm{dL}$ and postprandial values around $140 \mathrm{mg} / \mathrm{dL}$ may be achieved.

In summary, patients with significant hyperglycemia benefit most from immediate insulin-based strategies aimed at improving glucose control, and those patients with stable glucose control should receive immediate carbohydrate restriction combined with meticulous adaptation of their individual antidiabetic regimen.

\section{Remodeling and Reperfusion}

The extent of LV remodeling corresponds to the infarct-related artery patency, infarct size, and ventricular loading conditions. Reverse LV remodeling postinfarction is typified by normalization of LV architecture, reduced LV size, and increased contractile function. Conventional pharmacotherapy for postMI HF includes ACE inhibitors or angiotensin-receptor blockers, $\beta$-blockers, aldosterone antagonists, and statins. By comparison, newer approaches, such as nitric oxide signaling pathway therapy, antioxidants, and antiinflammatory therapy, have yielded conflicting or neutral results.

Optimal therapy in acute MI is early revascularization of the infarct-related coronary artery territory. Early reperfusion is associated with several benefits, such as reduction of infarct size, preservation of myocardial function, and decreased mortality. However, clinical benefits of late reperfusion of an occluded infarct-related coronary artery beyond the period of myocyte salvage are controversial and also poorly defined [97, 98]. The most recent AMICI (Acute Myocardial Infarction Contrast Imaging) study [99] on reverse remodeling after ST-elevated MI in patients treated with percutaneous coronary intervention (PCI) demonstrated that reverse remodeling was an important predictor of favorable long-term outcome that can be achieved in $39 \%$ of the patients. Furthermore, preserved microvascular perfusion within the infarct zone was the major determinant of reverse remodeling as assessed by myocardial contrast echocardiography perfusion studies. This extends earlier reports based on myocardial contrast echocardiography that had demonstrated the relevance of intact microvascular perfusion for the salvage of myocardium at PCI and the unexpected high frequency of blocked microcirculation in spite of patency of the epicardial artery $(25 \%-30 \%)$. This so-called no-reflow phenomenon is associated with poorer functional recovery and outcome. Two more recent studies confirmed the impact of diabetes on myocardial reperfusion and the no-reflow phenomenon $[16,100]$. In the AMICI trial, the observed trend for a larger prevalence of diabetes in the patients with LV remodeling versus those with reverse remodeling is in accordance with the known abnormalities of coronary flow reserve, endothelial function, ischemic preconditioning, and prothrombotic state in these patients. Theoretically, an optimized metabolic milieu of the diabetic myocardium with normalization of insulin resistance and lipotoxic or glucotoxic effects is warranted before the revascularization procedure to improve outcome. Given the immediate dynamic response of metabolic regulations, such causal metabolic therapy should be started immediately upon hospital admission.

\section{Conclusions}

Insulin resistance and HF post-MI are strongly related and signify a poor clinical outcome, especially in patients with diabetes. The myocardial metabolic milieu acts at the vascular and functional levels to derange perfusion and function to a substantial but hitherto unrecognized extent. This is partially explained by a lack of crosstalk between the respective cardiovascular and endocrinologic specialists. The causal relationship of insulin resistance and reduced cardiac function 
renders normalization of insulin resistance essential. The impact of carbohydrate restriction and weight reduction in the setting of acute MI and revascularization need to be elucidated. Future work is needed to clarify the significance and utility of novel pharmaceutical therapies for diabetes and insulin resistance.

Disclosures No potential conflicts of interest relevant to this article have been reported.

Open Access This article is distributed under the terms of the Creative Commons Attribution Noncommercial License which permits any noncommercial use, distribution, and reproduction in any medium, provided the original author(s) and source are credited.

\section{References}

Papers of particular interest, published recently, have been highlighted as:

- Of importance

-• Of major importance

1. Zimmet P, Alberti KG, Shaw J. Global and societal implications of the diabetes epidemic. Nature. 2001;414:782-7.

2. Ingelsson E, Sundstrom J, Arnlov J, et al. Insulin resistance and risk of congestive heart failure. JAMA. 2005;294:334-41.

3. From AM, Leibson CL, Bursi F, et al. Diabetes in heart failure: prevalence and impact on outcome in the population. Am J Med. 2006;119:591-9.

4. Redfield MM, Jacobsen SJ, Burnett JC, et al. Burden of systolic and diastolic ventricular dysfunction in the community - appreciating the scope of the heart failure epidemic. JAMA. 2003;289:194-202.

5. •• Borlaug BA, Paulus WJ. Heart failure with preserved ejection fraction: pathophysiology, diagnosis and treatment. Eur Heart J. 2011;32:670-9. This thorough review considers the complex pathophysiologic and morphologic alterations in the myocardium for diastolic action and dysfunction along with diagnostic algorithms, combined with a discussion of the need for their evaluation.

6. Malmberg K, Rydén L, Hamsten A, et al. Effects of insulin treatment on cause-specific 1-year mortality and morbidity in diabetic patients with acute myocardial infarction. DIGAMY Study Group. Diabetes insulin-glucose in acute myocardial infarction. Eur Heart J. 1996;17:1337-44.

7. Solomon SD, St John Sutton M, Lamas G, et al. Ventricular remodeling does not accompany the development of heart failure in diabetic patients after myocardial infarction. Circulation. 2002;106:1251-5.

8. Landmesser U, Wollert KC, Drexler H. Potential novel pharmacological therapies for myocardial remodelling. Cardiovasc Res. 2009;81:519-27.

9. Peterson LR, Herrero P, McGill J, et al. Fatty acids and insulin modulate myocardial substrate metabolism in humans with type 1 diabetes. Diabetes. 2008;57:32-40.

10. How OJ, Aasum E, Severson EL, et al. Increased myocardial oxygen consumption reduces cardiac efficiency in diabetic mice. Diabetes. 2006;55:466-73.

11. Hansen A, Johansson BL, Wahren J, et al. Beneficial effects of C-peptide on myocardial function and perfusion in patients with type 1 diabetes. Diabetes. 2002;51:3077-82.
12. von Bibra H, Thrainsdottir IS, Hansen A, et al. Tissue Doppler imaging for the detection and quantitation of myocardial dysfunction in patients with type 2 diabetes mellitus: a methodological study. Diabetes Vasc Dis Res. 2005;2:483-7.

13. Dounis V, Siegmund T, Jensen J, et al. Global myocardial perfusion and diastolic function are impaired to a similar extent in patients with type 2 diabetes mellitus and in patients with CAD - evaluation by contrast echocardiography and pulsed tissue Doppler. Diabetologia. 2006;49:2729-40.

14. Antonini-Canterin F, Carerj S, Di Bello V, et al. Arterial stiffnes and ventricular stiffness: a couple of diseases or a coupling disease? A review from the cardiologist's point of view. Eur J Echocardiogr. 2009;10:36-43.

15. Scuteri A, Najjar SS, Muller DC, et al. Metabolic syndrome amplifies the age-associated increases in vascular thickness and stiffness. J Am Coll Cardiol. 2004;43:1388-95.

16. Prasad A, Stone GW, Stuckey TD, et al. Impact of diabetes mellitus on myocardial perfusion after primary angioplasty in patients with acute myocardial infarction. J Am Coll Cardiol. 2005;45:508-14.

17. Kaul S. Myocardial contrast echocardiography-a 25-year retrospective. Circulation. 2008;118:291-308.

18. Porter TR, Xie F. Myocardial perfusion imaging with contrast ultrasound. J Am Coll Cardiol Cardiovasc Imaging. 2010;3:17687.

19. Anderson RA, Evans ML, Ellis GR, et al. The relationship between post-prandial lipemia, endothelial function and oxidative stres in healthy individuals and patients with type 2 diabetes. Atherosclerosis. 2001;154:475-83.

20. Ceriello A, Taboga C, Tonutti L, et al. Evidence for an independent and cumulative effect of postprandial hypertriglyceridemia and hyperglycemia on endothelial dysfunction and oxidative stress generation: effects of short- and long term simvastatin treatment. Circulation. 2002;106:1211-8.

21. Scognamiglio R, Negut C, De Kreutzenberg SV, et al. Postprandial myocardial perfusion in healthy subjects and in type 2 diabetic patients. Circulation. 2005;112:179-84.

22. von Bibra H, Hansen A, Dounis V, et al. Insulin based improved metabolic control augments myocardial diastolic function and perfusion in patients with type 2 diabetes mellitus. Heart. 2004;90:1483-4.

23. Scognamiglio R, Negut C, De Kreutzenberg S, et al. Effects of different insulin regimens on postprandial myocardial perfusion defects in type 2 diabetic patients. Diabetes Care. 2006;29:95100.

24. Coretti MC, Anderson TJ, Benjamin EJ, et al. Guidelines for the ultrasound assessment of flow-mediated vasodilatation of the brachial artery: a report of the International Brachial Artery Reactivity Task Force. J Am Coll Cardiol. 2002;39:257-65.

25. Carabba N, Valenti R, Parodi G, et al. Left ventricular remodeling and heart failure in diabetic patients treated with primary angioplasty for acute myocardial infarction. Circulation. 2004;110:1974-9.

26. Fang ZY. Diabetic cardiomyopathy: evidence, mechanisms and therapeutic implications. Endocr Rev. 2004;25:543-67.

27. •• von Bibra H, St John Sutton M. Diastolic dysfunction in diabetes and the metabolic syndrome: promising potential for diagnosis and prognosis. Diabetologia 2010;53:1033-45. This review considers the complex pathophysiologic pathways linking the metabolic diseases, diabetes mellitus, or the metabolic syndrome to diastolic function and highlights the potential and limitations of the present noninvasive imaging techniques to measure diastolic function and dysfunction.

28. - van Heerebeek L, Hamdani N, Handoko L, et al. Diastolic stiffness of the failing heart: importance of fibrosis, advanced glycation endproducts and myocyte resting tension. Circulation 
2008;117:43-51. This is an elegant study using endocardial biopsy specimen of systolic and diastolic heart failure in patients with diabetes. Matrix alterations with fibrosis and/or advanced glycation end products characterize systolic heart failure, whereas diastolic heart failure is associated with increased resting tension.

29. Serizawa T, Vogel WM, Apstein CS, et al. Comparison of acute alterations in left ventricular relaxation and diastolic chamber stiffness induced by hypoxia and ischemia. J Clin Invest. 1980;68:91-102.

30. Boudina S, Abel ED. Mitochondrial uncoupling: a key contributor to reduced cardiac efficiency in diabetes. Physiology. 2006;21:250-8.

31. Kenchaiah S, Sesso HD, Levy D, et al. Body mass index and vigorous physical activity and the risk of heart failure among men. Circulation. 2009;119:44-52.

32. Boudina S, Dale Abel E. Diabetic cardiomyopathy revisited. Circulation. 2007;115:3213-23.

33. •- Falk Peterson K, Dufour S, Savage DB, et al. The role of skeletal muscle insulin resistance in the pathogenesis of the metabolic syndrome. PNAS 2007;104:12587-94. This is a creative study linking myocellular metabolism of skeletal muscle with hepatic metabolic action in healthy but sedentary individuals with insulin resistance in whom postmeal glycogen synthesis in skeletal muscle is reduced and shifted to hepatic de novo triglyceride generation.

34. McGavock JM, Lingvay I, Zib I, et al. Cardiac steatosis in diabetes mellitus - $\mathrm{a}{ }^{1} \mathrm{H}$-magnetic resonance spectroscopy study. Circulation. 2007;116:1170-5.

35. Rijzewjik LJ, van der Meer RW, Smit JW, et al. Myocardial steatosis is an independent predictor of diastolic dysfunction in type 2 diabetes mellitus. J Am Coll Cardiol. 2008;52:1793-9.

36. Sinnaeve PR, Steg PG, Fox KA, et al. Association of elevated fasting glucose with increased short term and 6 month mortaliy in ST-segment elevation and non ST-segment elevation acute coronary syndromes: the Global Registry of Acute Coronary Events. Arch Intern Med. 2009;169:402-9.

37. Iribarren C, Karter AJ, Go AS, et al. Glycemic control and heart failure among adult patients with diabetes. Circulation. 2001;103:2668-73.

38. •• Witteles RM, Fowler MB. Insulin-resistant cardiomyopathy. J Am Coll Cardiol. 2008;51:93-102. This review considers the complex pathophysiologic pathways linking insulin-resistance metabolism and disturbed myocardial function and discusses therapeutic options.

39. Taegtmeyer H, McNulty P, Young ME. Adaptation and maladaptation of the heart in diabetes. I. General concepts. Circulation. 2002;105:1727-33.

40. Williams SB, Goldfine AB, Timimi FK, et al. Acute hyperglycemia attenuates endothelium-dependent vasodilatation in humans. Circulation. 1998;97:1695-701.

41. Roden M. How free fatty acids inhibit glucose utilization in human skeletal muscle. News Physiol Sci. 2004;19:92-6.

42. Mathews DR, Hosker JP, Rudensky AS, et al. Homeostasis model assessment: insulin resistance and $\beta$-cell function from fasting plasma glucose and insulin concentrations in man. Diabetologia. 1985;28:412-9.

43. Haffner SM, Gonzales C, Mykkänen L, et al. Total immunoreactive proinsulin, immunoreactive insulin and specific insulin in relation to conversion to type 2 diabetes. Diabetologia. 1997;40:830-7.

44. Pfützner A, Kunt T, Mondok A, et al. Fasting intact proinsulin is a highly specific predictor of insulin resistance in type 2 diabetes. Clin Lab. 2004;50:567-73.

45. Hohberg C, Pfützner A, Forst T, et al. Successful switch from insulin therapy to treatment with pioglitazone in type 2 diabetes patients with residual $\beta$-cell function: results from the PioSwitch Study. Diabetes Obes Metab. 2009;11:464-71.

46. •- Pfützner A, Forst T. Elevated intact proinsulin levels are indicative of beta-cell dysfunction, insulin resistance and cardiovascular risk: impact of the antidiabetic agent pioglitazone. J Diabetes Sci Technol. 2011;5:784-93. This comprehensive review introduces a scheme to stage type 2 diabetes according to the presence of intact proinsulin, a precursor of insulin, in relation to insulin.

47. Monnier L, Mas E, Ginet C, et al. Activation of oxidative stress by acute glucose fluctuations compared with sustained chronic hyperglycemia in patients with type 2 diabetes. JAMA. 2006;295:1681-7.

48. Yip G, Wang M, Zhang Y, et al. Left ventricular long axis function in diastolic heart failure is reduced in both diastole and systole: time for a redefinition? Heart. 2002;87:121-5.

49. Kasner M, Westermann D, Steendijk P, et al. Utility of Doppler echocardiography and tissue Doppler imaging in the estimation of diastolic function in heart failure with normal ejection fraction - a comparative Doppler-conductance catheterization study. Circulation. 2007;116:637-47.

50. Paulus WJ, Tschöpe $\mathrm{C}$, Rusconi $\mathrm{C}$, et al. How to diagnose diastolic heart failure: a consensus statement on the diagnosis of heart failure with normal left ventricular ejection fraction by the Heart Failure and Echocardiography Associations of the European Society of Cardiology. Eur Heart J. 2007;28:2539-50.

51. Nagueh SF, Appleton CP, Gillebert TC, et al. Recommendations for the evaluation of left ventricular diastolic function by echocardiography. J Am Soc Echocardiogr. 2009;22:107-33.

52. Wijns W, Serruys PW, Slager C, et al. Effect of coronary occlusion during percutaneous transluminal angioplasty in humans on left ventricular chamber stiffness and regional diastolic pressure-radius relations. J Am Coll Cardiol. 1986; 7:455-63.

53. Charlat ML, O'Neill PG, Hartley CJ, et al. Prolonged abnormalities of left ventricular diastolic wall thinning in the "stunned" myocardium in conscious dogs: time course and relation to systolic function. J Am Coll Cardiol. 1989;13:185-94.

54. von Bibra H, Tuchnitz A, Klein A, et al. Regional diastolic function by pulsed Doppler myocardial mapping for the detection of left ventricular ischaemia during pharmacologic stress testing - a comparison with stress echocardiography and perfusion scintigraphy. J Am Coll Cardiol. 2000;36:44452.

55. Bess RL, Rosman HS, Cohen GI, et al. Technical aspects of diastology: why mitral inflow and tissue Doppler imaging are the preferred parameters? Echocardiography. 2006;23:332-9.

56. Mulvagh S, Rakowski H, Vannan MA, et al. American Society of Echocardiography consensus statement on the clinical applications of ultrasonic contrast agents in echocardiography. J Am Soc Echocardiogr. 2008;21:1179-201.

57. Senior R, Becher H, Monaghan M, et al. Contrast echocardiography: evidence-based recommendations by European Association of Echocardiography. Eur J Echocardiogr. 2009;10:194-212.

58. •-Villanueva FS. Myocardial perfusion imaging using ultrasound contrast agents - now or never? J Am Coll Cardiol Cardiovascular Imaging 2010;3:944-6. This is a knowledgeable consideration of the potential of myocardial contrast echocardiography, its clinical value, and the potential reasons for the delay in acceptance by clinicians.

59. Gropler RJ, Beanlands RS, Dilsizian V, et al. Imaging myocardial metabolic remodeling. J Nucl Med. 2010;51:88-101.

60. American Diabetes Association. Nutrition recommendations and interventions for diabetes. Diabetes Care. 2008;31 Suppl 1:61-78.

61. Mann JI, Hermansen K, Karamanos B, on behalf of the Diabetes and Nutrition Study Group (DNSG) of the European Association 
for the Study of Diabetes (EASD), et al. Evidence-based nutritional approaches to the treatment and prevention of diabetes mellitus. Nutr Metab Cardiovasc Dis. 2004;14:373-94.

62. •- Marantz PR, Bird ED, Alderman MH. A call for higher standards of evidence for dietary guidelines. Am J Prev Med. 2008;34:234-40. This is a 30-year observation on fat intake, carbohydrate consumption, and body weight development in American men and women, leading to the insight that dietary guidelines need higher standards of evidence to avoid damage on a population level.

63. Yusuf S, Hawken S, Ounpuu S, on behalf of the INTERHEART Study investigators. Effect of potentially modifiable risk factors associated with myocardial infarction in 52 countries (the INTERHEART study): case-control study. Lancet. 2004;364:937-52.

64. •• Accurso A, Bernstein RK, Dahlqvist A, et al. Dietary carbohydrate restriction in type 2 diabetes mellitus and metabolic syndrome: time for a critical appraisal. Nutr Metab. 2008;5:9-17. This sound and basic review focuses on physiologic mechanisms working in diabetes metabolism and critically discusses the respective nutritional recommendations and pharmacological treatments.

65. - Buyken AE, Mitchell P, Ceriello A, et al. Optimal dietary approaches for prevention of type 2 diabetes: a life-course perspective. Diabetologia 2010;53:406-18. This thorough review considers the complex pathophysiologic and metabolic alterations in type 2 diabetes potentially leading to heart failure, along with diagnostic algorithms and a thorough discussion about the large field of literature on antidiabetic treatment.

66. Elhayany A, Lustman A, Abel R, et al. A low carbohydrate Mediterranean diet improves cardiovascular risk factors and diabetes control among overweight patients with type 2 diabetes mellitus: a 1-year prospective randomized intervention study. Diabetes Obes Metab. 2010;12:204-9.

67. Shai I, Schwarzfuchs D, Henkin Y, et al. Weight loss with a low carb, Mediterranean, or low fat diet. New Engl J Med. 2008;359:229-41.

68. Rallidis LS, Lekakis J, Kolomvotsou A, et al. Close adherence to a Mediterranean diet improves endothelial function in subjects with abdominal obesity. Am J Clin Nutr. 2009;90:263-8.

69. Volek JS, Ballard KD, Silvestre R, et al. Effects of dietary carbohydrate restriction vs low-fat diet on flow mediated dilatation. Metab Clin Exp. 2009;58:1769-77.

70. von Bibra H, Wulf G, Schumm-Draeger PM, et al. Cardiac function and insulin resistance improved by a low-glycemic/ high-protein diet but not by low-fat diet in overweight type 2 diabetes patients abstract. Diabetes. 2010;59 suppl 1:A124.

71. Hammer S, Snel M, Lamb HJ, et al. Prolonged caloric restriction in obese patients with type 2 diabetes mellitus decreases myocardial triglyceride content and improves myocardial function. J Am Coll Cardiol. 2008;52:1006-12.

72. Rider OJ, Francis JM, Ali MK, et al. Beneficial cardiovascular effects of bariatric surgical and dietary weight loss in obesity. J Am Coll Cardiol. 2009;54:718-26.

73. Maruthur NM, Wang NY, Appel LJ. Lifestyle interventions reduce coronary heart disease risk-results from the PREMIER trial. Circulation. 2009;119:2026-31.

74. Eurich DT, Majumdar SR, McAlister FA, et al. Improved clinical outcomes associated with metformin in patients with diabetes and heart failure. Diabetes Care. 2005;28:2345-51.

75. UK Prospective Diabetes Study (UKPDS) Group. Effect of intensive blood-glucose control with metformin on complications in overweight patients with type 2 diabetes (UKPDS 34). Lancet. 1998;352:854-65.

76. Anderson C, Sogaard P, Hoffmann S, et al. Metformin is associated with improved left ventricular diastolic function measured by tissue Doppler imaging in patients with diabetes. Eur J Endocrinol. 2010;163:593-9.
77. Khurana R, Malik IS. Metformin, safety in cardiac patients. Postgrad Med J. 2010;86:371-3.

78. Eurich DT, McAlicster FA, Blackburn DF, et al. Benefits and harms of antidiabetic agents in patients with diabetes and heart failure: systematic review. BMJ. 2007;335:497-507.

79. Nesto RW, Bell D, Bonow RO, et al. Thiazolidinedione use, fluid retention, and congestive heart failure: a consensus statement from the American Heart Association and the American Diabetes Association. October 7, 2003. Circulation. 2003;108:2941-8.

80. Guan Y, Hao C, Cha DR, et al. Thiazolidinediones expand body fluid volume through PPARgamma stimulation of EnaCmediated renal salt absorption. Nat Med. 2005;11:861-6.

81. van der Meer RW, Rijzewijk LJ, de Jong HW, et al. Pioglitazone improves cardiac function and alters myocardial substrate metabolism without affecting cardiac triglyceride accumulation and high-energy phosphate metabolism in patients with wellcontrolled type 2 diabetes mellitus. Circulation. 2009;119:206977.

82. Dargie HJ, Hildebrandt PR, Riegger GA, et al. A randomized, placebo-controlled trial assessing the effects of rosiglitazone on echocardiographic function and cardiac status in type 2 diabetic patients with the New York Heart Association functional class I-II heart failure. J Am Coll Cardiol. 2007;49:1696-704.

83. Masoudi FA, Inzucchi SE, Wang Y, et al. Thiazolidinediones, metformin and outcomes in older patients with diabetes and heart failure: an observational study. Circulation. 2005;111:583-90.

84. Inzucchi SE, Masoudi FA, Wang Y, et al. Insulin-sensitizing antihyperglycemic drugs and mortality after acute myocardial infarction: insights from the National Health Care Project. Diabetes Care. 2005;28:1680-9.

85. Nystrom T, Gutniak MK, Zhang Q, et al. Effects of glucagon-like pepetide- 1 on endothelial function in type 2 diabetes patients with stable coronary artery disease. Am J Physiol Endocrinol Metab. 2004;287:E1209-15.

86. Basu A, Charkoudian N, Schrage W, et al. Beneficial effects of GLP-1 on endothelial function in humans: dampening by glyburide but not by glimepiride. Am J Physiol Endocrinol Metab. 2007;293:E1289-95.

87. Nikolaidis LA, Mankad S, Sokos GG, et al. Effects of glucagonlike peptide- 1 in patients with acute myocardial infarction and left ventricular dysfunction after successful reperfusion. Circulation. 2004;109:962-5.

88. Sokos GG, Bolukoglu H, German J, et al. Effect of glucagon-like peptide-1 (GLP-1) on glycemic control and left ventricular function in patients undergoing coronary artery bypass grafting. Am J Cardiol. 2007;100:824-9.

89. Sokos GG, Nikolaidis LA, Mankad S, et al. Glucagon-like peptide-1 infusion improves left ventricular ejection fraction and functional status in patients with chronic heart failure. J Card Fail. 2006;12:694-9.

90. Bunck MC, Cornér A, Eliasson B, et al. One year treatment with exenatide vs insulin glargine: effects on postprandial glycemia, lipid profiles and oxidative stress. Atherosclerosis. 2010;212:223-9.

91. Schwartz EA, Koska J, Mullin MP, et al. Exenatide suppresses postprandial elevations in lipids and lipoproteins in individuals with impaired glucose tolerance and recent onset type 2 diabetes mellitus. Atherosclerosis. 2010;212:217-22.

92. Koska J, Schwartz E, Mullin MP, et al. Improvement of postprandial endothelial function after a single dose of exenatide in individuals with impaired glucose tolerance and recent-onset type 2 diabetes. Diabetes Care. 2010;33:1028-30.

93. Read PA, Khan FZ, Heck PM, et al. DPP-4 inhibition by sitagliptin improves the myocardial response to dobutamine stress and mitigates stunning in a pilot study of patients with CAD. Circ Cardiovasc Imaging. 2010;3:195-201. 
94. •• De Caterina R, Madonna R, Sourij H, et al. Glycemic control in acute coronary syndromes: prognostic value and therapeutic options. Eur Heart J. 2010;31:1557-64. This review discusses the large amount of pharmaceutical studies that attempted to improve patient's outcome via normalization of hyperglycemia and resulted in inconclusive findings.

95. Deedwania P, Kosiborod M, Barrett E, et al. Hyperglycemia and acute coronary syndrome: a scientific statement from the American Heart Association Diabetes committee of the Council of Nutrition, Physical Activity and Metabolism. Circulation. 2008;117:1610-9.

96. Van de Werf F, Bax J, Betrui A, et al. Management of acute myocardial infarction in patients presenting with persistent STsegment elevation: the Task Force on the Management of STSegment Elevation Acute Myocardial Infarction of the European Society of Cardiology. Eur Heart J. 2008;29:2909-45.
97. Hochmann JS, Lamas GA, Buller CE, et al. Coronary intervention for persistent occlusion after myocardial infarction. N Engl J Med. 2006;355:2395-407.

98. Appleton DL, Abbate A, Biondi-Zoccai GG, et al. Late percutaneous coronary intervention for the totally occluded infarct-related artery: a meta-analysis of the effects of cardiac function and remodeling. Catheter Cardiovasc Interv. 2008;71:772-81.

99. Funaro S, La Torre G, Madonna M, et al. Incidence, determinants and prognostic value of reverse left ventricular remodelling after primary percutaneous coronary intervention: results of the Acute Myocardial Infarction Contrast Imaging (AMICI) multicenter study. Eur Heart J. 2009;30:566-75.

100. Iwakura $\mathrm{K}$, Ito $\mathrm{H}$, Ikushima $\mathrm{M}$, et al. Association between hyperglycemia and the no-reflow phenomenon in patients with acute myocardial infarction. J Am Coll Cardiol. 2003;41:1-7. 